\title{
Factors Determining the Retention of Academic Staff in Universities
}

\author{
Kizza Francis Ssali \\ East African School of Higher Education Studies and Development, Makerere University \\ P. O Box 7062, Kampala, Uganda \\ David Onen* \\ East African School of Higher Education Studies and Development, Makerere University \\ P. O Box 7062, Kampala, Uganda \\ Genza Gyaviira Musoke \\ School of Education, Makerere University, P. O Box 7062, Kampala, Uganda
}

\begin{abstract}
The research is privately financed by the researchers.
\end{abstract}
\section{Abstract}

This paper examines the critical factors that determine the retention of academic staff at Makerere and Kyambogo universities in Uganda. The study was prompted by reportedly persistent low levels of academic staff retention in the two public universities in the recent past. The investigation followed the positivist research paradigm. The study employed the descriptive cross-sectional survey design where data were collected using an adapted selfadministered questionnaire from 298 academic staff proportionately drawn from the two universities studied. The staff respondents were sampled through stratified random sampling technique. The data were analysed with the use of descriptive statistics such as frequencies, percentages, means and standard deviations as well as inferential statistics like student t-test, Analysis of Variance (ANOVA), and regression analyses. Study findings revealed that respondent's marital status $(F=0.288 ; p=0.750>0.05)$, age $(F=0.748 ; p=0.560>0.05)$, experience $(F=0.270$; $\mathrm{p}=0.841>0.05)$, education level $(\mathrm{F}=0.528 ; \mathrm{p}=0.663>0.05)$, and interpersonal relationships $(\mathrm{B}=0.003 ; \mathrm{p}=$ $0.957>0.05)$ had statistically no significant effect on the retention of academic staff in the two universities. However, respondent's gender $(t=2.556 ; p=0.006<0.05)$, terms of work $(B=0.163 ; p=0.005<0.05)$ and worklife balance $(\mathrm{B}=0.318 ; \mathrm{p}=0.000<0.05)$ were found to have statistically significant effects on the retention of academic staff. Thus, it was concluded that certain factors were more critical than others in determining the retention of academic staff, other factors notwithstanding. The researchers therefore recommended that the management of the two universities should design engendered policies that would improve on the terms of work, favourably treat men and women, and allow for optimal work-life balance amongst their academic staff.

Keywords: Academic staff, Retention, Factors, Demographic characteristics, Interpersonal relationships, Terms of work, Work-life balance

DOI: $10.7176 / \mathrm{JEP} / 10-8-07$

Publication date:March $31^{\text {st }} 2019$

\section{Introduction}

World over, university teaching jobs are considered by many, not only as being prestigious and competitive, but lucratic as well. In Africa, for long, teaching at university has not only been regarded noble, but a dream comes true for many individuals. But this does not seem to be true anymore. If any, the nostalgia for acquiring and settling down in university employment may now only be strong amongst those who are unsuitable for the jobs. Otherwise, if teaching in university was still such a revered job, then what would explain the acute shortage of academic staff experienced nowadays by many African universities amidst the rising numbers of qualified Africans? In Uganda in particular, public universities have been failing to attract and retain highly qualified individuals for their teaching jobs. This has resulted into acute shortage of academic staff that appears to be already hurting the quality of university education in the country. In this study, the researchers examined the critical factors that determine the retention of academic staff in Makerere and Kyambogo universities, two of the oldest and largest public universities in Uganda. In this section, the authors present the background and the objectives of the study.

Historically, the problem of low retention of employees in work organisations is not a new phenomenon. In higher education, this problem is gaining ground in many countries. For instance Miller (2013) and Albaqami (2016) revealed that in the United States of America, around 20 percent of public university faculty leaves their positions annually. In Australian higher education institutions, Ngethe, Namusonge and Irvo (2012) reported that up to 68 percent of academic staff left their positions in different universities in a short period of time. Tettey (2006) also revealed that about 7.7 percent of full-time academic staff in African universities left their institutions for others places within one academic year (between 1997 and 1998). Of these academic staff who left, Tettey revealed that only 29 percent of them were retirees while the remaining 71 percent left for diverse reasons. But 
according to Gbenu (2013), the problem of low staff retention is on the increase especially on the African continent where 23,000 qualified academic staffs migrate each year from the continent in search for better working conditions in Europe and the Americas. However, none of these studies focused on the critical factors affecting the retention of academic staff in universities in Uganda; thus, the genesis of this study.

Theoretically, this study was anchored on two key theories, namely: the job embbededness (JET) and organisational support (OST) theories. The JET was propounded by Mitchell, Holtom, Lee, Sablynski and Erez in 2001 and states that for an employee to stay on his/her current job there must be links, fits and sacrifices within the work organisation (Young, Aliang \& Shuck, 2013). According to the theory, an employee would prefer to stay and work for an organization if there are appropriate social, psychological, financial, and biographic links between $\mathrm{him} /$ her and the organization. This, according to Young et al. (2013), is what is referred to as links. Second, the theory postulates that an employee would be willing to stay and work for an organisation if he/she perceives the work organisation to be comfortable or conducive. This is what is termed as fits (Holmes, Burghurst \& Chapman, 2013). Third, the theory states that an employee would wish to stay and work for an organisation for fear of losing material and other psychological benefits. This, according to Lee, Birch and Mitchell (2013), is referred to as sacrifice. In the study, JET was preferred for three reasons. First, the researchers hypothesized that academic staff in Makerere and Kyambogo universities may be leaving their employment due to their lack of links between their social, psychological, financial and biographic factors and what the universities offer. Second, the low rate of academic staff retention could be arising from lack of fit between the individual employees and the work environment which they may perceive to be uncomfortable and unconducive. Finally, the low staff retention may be due to less fear for losing either material or psychological benefits upon leaving their jobs.

The second theory that was used to guide this study was the organizational support theory (OST) that was propounded by Eisenberger, Huntington, Hutchison and Sowa in 1986 (Baker, Mohamad \& Sharmeela-Banu, 2015). This theory states that when employees believe that the organisation values and supports them in their work, then they would decide to stay and work for that organisation (Vardaman, et al., 2016). In this study, the theory was opted for in order to examine the effect of interpersonal relationships on the retention of academic staff in the universities studied.

In this study, there were five key concepts that were investigated, namely: demographic characteristics, interpersonal relationships, terms of work, work-life balance and staff retention. According to Hong, Hao, Kumar, Ramendran and Kadiresan (2012), staff retention refers to the prevention of valuable employees from leaving their current jobs. It involves managers taking measures to encourage employees to remain in an organisation for a maximum period of time. Janhua (2016) meanwhile defined staff retention as the ability to hold onto those employees which an organization wants to keep for longer than their competitors. In this study, the retention of academic staff was looked at in terms of the staff's intent to stay on their job, their continued service delivery, the intent to remain and keep on the job, the individual sense of belonging, and stability on the current job.

The second concept in the study was demographic characteristics. The term demographic characteristics refer to those features used to distinguish groups of a population such as gender, age, and marital status (Vandenberghe \& Ok, 2013). In this study, demographic characteristics were looked at in terms of gender, educational levels, marital status, age, and the experience of the academic staff.

The third concept was interpersonal relationships. According to Long, Ajagbe, Nor, and Suleiman (2012), interpersonal relationships refers to the maintenance of a healthy working relationships between management and the employees, and amongst the employees themselves. In this study, interpersonal relationships were looked at in terms of lecturer to lecturer, lecturer to administrators, lecturer to student, and lecturer to non-teaching staff relationships.

The fourth concept in this study was terms of work. According to Tanwar and Prasad (2016), terms of work refers to work conditions offered to an employee after being appointed on a job. Terms of work in this study was looked at in terms of: job security, promotion procedures, and job benefits.

Finally, work-life balance was another key concept that was investigated in this study. According to Coetze, Osthuizen and stoltz (2015), work-life balance refers to the employee's perception of harmony or conflict between work and life. However, Kubler and Deluca (2006) defined work-life balance as the degree to which an individual is equally engaged at work and in satisfying his/her family roles. In this study, work-life balance was looked at in terms: one's teaching load, lecture to student ratio, meeting of deadlines, amount of responsibilities assigned, number of student supervisees assigned, flex time, taking of holiday and leave opportunities.

Contextually, this study took place at Makerere and Kyambogo universities. According to the Uganda's Auditor General's Report of 2015, out of 2,774 established academic staff positions for Makerere University, only 1,333 (or 48 percent) were filled - leaving a gap of 1,441 (or 52 percent). Meanwhile, the same report revealed that out of 1,556 established posts for Kyambogo University, only 837 (or 54 percent) were filled - leaving a gap of 46 percent posts. These reports were corroborated by the recent Rwendeire Committee Report of 2017 which revealed that Makerere University has continued to lose its staff at a worrying rate. For instance, the report indicated that between 2015 and 2016 alone, the University lost over 69 senior academic staff. The story is not 
any different for Kyambogo University and the rest of other public universities. These statistics are not only perturbing, but are pointers to yet bigger problems to come in the provision of quality higher education. These reports may as well prompt us to ask: why are Makerere and Kyambogo universities failing to retain qualified academic staff? In this study, the researchers attempted to investigate the factors that determine the retention of academic staff in the two universities.

\subsection{Study Objectives}

Overall, the study examined the critical factors that determine the retention of academic staff in Makerere and Kyambogo universities. Specifically, it was meant to: (1) establish whether demographic characteristics; (2) interpersonal relationships; (3) terms of work; and (4) work-life balance determine the retention of academic staff in the two universities.

\subsection{Research Hypotheses}

The study aimed to verify the following research hypotheses: (1) Demographic characteristics significantly determine the retention of academic staff; (2) Interpersonal relationships significantly determine the retention of academic staff; (3) Terms of work significantly determine the retention of academic staff; and (4) Work-life balance significantly determines the retention of academic staff.

\section{Literature Review}

Several scholars have already investigated different factors that determine the retention of academic staff in different institutions. Some of these studies looked at the impact of demographic factors such as age (Victoria \& Olalekan, 2016; Ngobeni \& Bezuidenhoint, 2011), academic qualifications (Hayes, 2015; Kyndt, Michielson \& Moeyaert, 2009), gender (Muir \& Li, 2014), and marital status (Janhua, 2016). All these studies emerged with different findings on the different demographic factors which determine the retention of academic staff in higher education institutions. Muir and $\mathrm{Li}$ (2014) for instance, discovered that the retention of men and women in US higher education institutions differ with women reporting relatively lower retention rates than men. According to the two authors, the lower retention rates of women in lower tenured positions were attributed to several factors including the low levels of socialisation and association which the men tend to enjoy in male dominated work settings. In this study, however, the researchers believe that the findings would be different from those of Muir and $\mathrm{Li}$ due to the differences in contextual factors since this study was undertaken in Africa. In a study on age, Victoria and Olalekan (2016) found out that age was significantly related with academic staff retention, with younger employees expressing greater intentions to leave than older ones. This finding however contradicted the work of Ngobeni and Bezuidenhoint (2011) who opined that the older the employees get, the higher the possibility of losing knowledge and skills; and consequently, the likelihood to retire from their jobs. In this study, the researchers intended to verify the two claims with reference to the academic staff in the two universities studied.

A few scholars have also looked at the impact of interpersonal relations on the retention of employees in work organisations. Erasmus, Gobler and Niekerk (2015) for instance investigated the relationship between managers and their employees in order to establish the employee's intent to stay or leave their current jobs. The study established that there is a positive significant relationship between interpersonal relationships that occurs between the managers and their employees. This finding was collaborated by Korantiwi-Barimah (2017) who revealed that collegiality between managers and staff tends to raise the rate of academic staff retention. But this finding was not in congruence with the work of Masum, Azam and Beh (2014) who established that interpersonal relations between supervisors and academic staff have no significant effect on the retention of academic staff in private universities in Bangladesh. In this study, the researchers wanted these contradictions further investigated and understood.

Some scholars have also investigated whether academic staff retention depends on terms of work. Rathakrihnan, Imm and Kok (2016) examined whether turnover intentions of lecturers in private universities in Malaysia was dependent on terms of work. The researchers established that there was significant relationship between lecturers' turnover intentions and terms of work - particularly lecturers' expectations of continuity on the job. Mapolisa (2014) also investigated the challenges of academic staff retention in public and private universities in Zimbabwe and discovered that the rate of staff retention heavily depended on their terms of work. In fact, her study revealed that junior academic staff had lower rate of retention than their senior counterparts who were favoured in terms of awarding them employment contracts. All these studies were however done in the context of other countries rather than Uganda, which this current study focused on.

Finally, some scholars also investigated whether academic staff retention in higher education institutions depended on employees' work-life balance. Nawaz, Jahanian and Tahreem (2012) for instance observed that the employees' loyalty and continued stay with their current work organisation was dependent on how comfortable the employees are with their existing work schedules. According to these authors, favourable workload and timing of tasks enable employees to balance their personal work and social life. Thus, the scholars opined that a favourable work-life balance often enhances the employee's personal productivity at work and home. In another study by 
Watanabe and Falci (2014), it was discovered that the intentions of academic staff to leave their current employment was significantly dependent on their family demands. The authors posited that high work pressures involving heavy workload such as actual teaching, supervision, marking and working with students outside class tend to drive away academic staff from their current jobs and the reverse is true. However, all these studies were also carried out in a different context with that of Makerere and Kyambogo universities.

\section{Methodology}

In the study, the researchers employed the descriptive, cross-sectional survey research design, where purely quantitative method of data collection and analysis were used. The descriptive design was opted for because the study was aimed at examining the critical factors that determine the retention of academic staff in Makerere and Kyambogo universities. Specifically, the researchers used the cross-sectional survey design. This was intended to allow the researchers to collect data from a cross-section of the academic staff of the two universities at one point in time in order to avoid wasting time returning to the field to collect additional data that would make the process rather time consuming and costly especially if the whole study was made longitudinal in design. In addition, using the survey design helped the researchers to generalise the study findings obtained from the sampled population to the targeted population of all academic staff in the two universities studied. During the study, data were collected from 298 academic staff (152 from Makerere University and 146 from Kyambogo University) using the survey method. The data were analysed with the use of descriptive statistics such as frequencies, percentages, means and standard deviations as well as inferential statistics like student t-test, Analysis of Variance (ANOVA), and regression analyses. During the study, appropriate ethical issues such as gender balance, informed consent and confidentiality were also put into considerations.

\section{Results}

This study was aimed at testing four null hypotheses, namely: (1) Demographic characteristics do not significantly determine the retention of academic staff; (2) Interpersonal relationships do not significantly determine the retention of academic staff; (3) Terms of work do not significantly determine the retention of academic staff; and (4) Work life balance does not significantly determine the retention of academic staff.

\subsection{Test of Hypothesis One}

Hypothesis one was stated as "demographic characteristics significantly determine the retention of academic staff". However, since demographic characteristics are comprised of different categorical dimensions such as gender, age, marital status and the like, the null hypotheses stated as "Demographic characteristics do not significantly determine the retention of academic staff" could not be tested as a single whole; instead, minor hypotheses in line with each demographic characteristic were derived and tested accordingly. In this first part, the researchers present the test of null hypotheses on the different demographic characteristics.

4.1.1. Respondent's gender and academic staff retention

The first null hypothesis on demographic characteristics that was tested concerned the effect of gender on the retention of academic staff in the two universities studied. To perform the test, an index called academic staff retention (ASR) was generated and a student-t test was employed to determine whether there was a statistically significant difference in the retention of academic staff by gender which was categorically and binary coded as female $(\mathrm{F}=1)$ and male $(\mathrm{M}=2))$. The t-test results are presented in Table 1 .

Table 1: Students t-test Results on Gender and Academic Staff Retention

\begin{tabular}{|l|l|l|l|lc|}
\hline Gender & Sample size & Sample mean $(\bar{x})$ & Sample SD & t & $p$ \\
\hline Male & 186 & 3.19 & 0.425 & 2.556 & 0.006 \\
\hline Female & 112 & 3.34 & 0.368 & & \\
\hline
\end{tabular}

The results in Table 1 showed that on average, female academic staff $(\bar{x}=3.34)$ scored on ASR marginally higher than their male counterparts $(\bar{x}=3.19)$. However, student- $\mathrm{t}(\mathrm{t}=2.556)$ was bigger because the probability or level of significance $(\mathrm{p}=0.006)$ was smaller than $\alpha=0.05(\mathrm{p}<0.05)$. This implied that the retention of academic staff significantly depended on their gender; that is, female staff appears to have better retention than their male counterparts. Therefore, the null hypothesis which states that "gender does not significantly determine the retention of academic staff" were rejected in favour of the research hypothesis which states that "gender significantly determines the retention of academic staff' in Makerere and Kyambogo universities.

4.1.2 Respondent's marital status and academic staff retention

The second null hypothesis on demographic characteristics that was tested concerned the effect of respondent's marital status on the retention of academic staff in the two universities studied. To perform the test, an index called academic staff retention (ASR) was generated and an Analysis of Variance (ANOVA) test was employed to determine whether there was a statistically significant difference in the retention of academic staff by marital status which was categorically and multi-coded as: Single $(\mathrm{S}=1)$, married $(\mathrm{M}=2)$ and Others $(\mathrm{O}=3))$. The ANOVA-test results are presented in Table 2 . 
Table 2: ANOVA Results on Academic Staff Retention by Respondent's Marital Status

\begin{tabular}{|l|l|l|l|l|l|}
\hline Marital status & Sample size & Sample mean $(\bar{x})$ & Sample SD & F & P \\
\hline Single & 51 & 3.264 & 0.442 & 0.288 & 0.750 \\
Married & 243 & 3.248 & 0.4015 & & \\
\hline Others (Specify) & 4 & 3.104 & 0.478 & & \\
\hline
\end{tabular}

Results in Table 2 show that the mean score on ASR was highest for single academic $\operatorname{staff}(\bar{x}=3.264)$, followed by married academic staff $(\bar{x}=3.248)$ and others $(\bar{x}=3.104)$. The computed $\mathrm{F}=0.288$ was small because the probability or level of significance $(p=0.750)$ was greater than $\alpha=0.05(p>0.05)$. This implied that the retention of academic staff did not significantly depend on their marital status; therefore, the null hypothesis which states that "marital status does not significantly determine the retention of academic staff" was accepted and the research hypothesis that states that "marital status significantly determines the retention of academic staff" was rejected. This means that marital status of academic staff does not determine whether they may stay or leave working for Makerere or Kyambogo University.

4.1.3. Respondent's rank and academic staff retention

The third null hypothesis on demographic characteristics that was tested concerned the effect of respondent's academic rank on the retention of academic staff in the two universities studied. To perform the test, an index called academic staff retention (ASR) was generated and an Analysis of Variance (ANOVA) test was employed to determine whether there was a statistically significant difference in the retention of academic staff by academic rank which was categorically and multi-coded as: Teaching assistant $(\mathrm{TA}=1)$, Assistant Lecturer $(\mathrm{AL}=2)$, Lecturer $(\mathrm{L}=3)$, Senior Lecturer $(\mathrm{SL}=4)$, Associated Professor $(\mathrm{AP}=5)$, and Professor $(\mathrm{P}=6)$. The ANOVA-test results are presented in Table 3.

Table 3: ANOVA Results on Respondent's Rank and Academic Staff Retention

\begin{tabular}{|c|c|c|c|c|c|}
\hline Current rank & Sample size & Sample mean $(\bar{x})$ & Sample SD & $\mathrm{F}$ & $\mathrm{P}$ \\
\hline Teaching assistant & 39 & 3.214 & 0.368 & \multirow[t]{6}{*}{0.457} & \multirow[t]{6}{*}{0.808} \\
\hline Assistant lecturer & 93 & 3.270 & 0.424 & & \\
\hline Lecturer & 93 & 3.239 & 0.92 & & \\
\hline Senior lecturer & 47 & 3.263 & 0.483 & & \\
\hline Associate professor & 13 & 3.347 & 0.446 & & \\
\hline Professor & 13 & 3.141 & 0.396 & & \\
\hline
\end{tabular}

The results in Table 3 indicated that the mean score on ASR was higher for Associate Professors $(\bar{x}=3.347)$, followed by Assistant Lecturers $(\bar{x}=3.270)$, followed by Senior Lecturers $(\bar{x}=3.263)$, followed by Lecturers $(\bar{x}=3.239)$. Lowest rating was witnessed on Professors $(\bar{x}=3.141)$. The computed $\mathrm{F}=0.457$ was small and the level of significance $(p=0.808)$ was larger than $\alpha=0.05(p>0.05)$. This implied that the retention of academic staff did not significantly depend on their academic rank; therefore, the null hypothesis which states that "academic ranks of staff do not significantly determine the retention of academic staff" was accepted and the research hypothesis that states that "academic ranks significantly determine the retention of academic staff" was rejected. This means that ranks of academic staff do not determine whether they may stay or leave working for Makerere or Kyambogo University.

4.1.4. Respondent's highest academic qualifications and academic staff retention

The fourth null hypothesis on demographic characteristics that was tested concerned the effect of respondent's highest academic qualifications on the retention of academic staff in the two universities studied. To perform the test, an index called academic staff retention (ASR) was generated and an Analysis of Variance (ANOVA) test was employed to determine whether there was a statistically significant difference in the retention of academic staff by marital status which was categorically and multi-coded as: Bachelor's Degree $(B=1)$, Master's Degree $(\mathrm{M}=2)$, Doctorate Degree $(\mathrm{D}=3))$, and Others $(\mathrm{O}=4)$. The ANOVA-test results are presented in Table 4.

Table 4: ANOVA Results on Respondent's Highest Academic Qualifications and Academic Staff Retention

\begin{tabular}{|l|l|l|l|c|c|}
\hline Qualification status & Sample size & Sample mean $(\bar{x})$ & Sample SD & F & p \\
\hline Bachelor's degree & 30 & 3.192 & 0.385 & 0.528 & 0.663 \\
\cline { 1 - 4 } Master's degree & 154 & 3.238 & 0.392 & & \\
\cline { 1 - 2 } & 111 & 3.283 & 0.432 & & \\
\hline
\end{tabular}

Table 4 results indicate that the mean score on ASR was higher for academic staff with $\mathrm{PhD}$ (mean of 3.283), followed by those with master's degree $(\bar{x}=3.238)$, followed by those with bachelor's degree $(\bar{x}=3.192)$ and those in the category of others had the lowest mean on retention (ASR). The computed observed $\mathrm{F}=0.528$ was low since the probability $(\mathrm{p}=0.663)$ was larger than $\alpha=0.05(\mathrm{p}>0.05)$. This implied that the retention of academic staff did not significantly depend on their highest academic qualifications; therefore, the null hypothesis which states that "highest academic qualifications of staff do not significantly determine the retention of academic staff" was accepted and the research hypothesis that states that "highest academic qualifications significantly determine 
the retention of academic staff' was rejected. This means that highest academic qualifications of academic staff do not determine whether they may stay or leave working for Makerere or Kyambogo University.

4.1.5. Respondent's years of teaching experience and academic staff retention

The fifth null hypothesis on demographic characteristics that was tested concerned the effect of respondent's years of teaching experience on the retention of academic staff in the two universities studied. To perform the test, an index called academic staff retention (ASR) was generated and an Analysis of Variance (ANOVA) test was employed to determine whether there was a statistically significant difference in the retention of academic staff by years of teaching experience which was categorically and multi-coded as: Less than 2 years (coded as 1), $2-5$ years (coded as 2), $6-10$ years (coded as 3)), and Above 10 years (coded as 4). The ANOVA-test results are presented in Table 5.

Table 5: ANOVA Results on Respondent's Years of Teaching Experience and Academic Staff Retention

\begin{tabular}{|l|l|l|l|c|c|}
\hline Teaching experience & Sample size & Sample mean $(\bar{x})$ & Sample SD & F & P \\
\hline Less than 2 years & 32 & 3.270 & 0.3168 & 0.27 & 0.841 \\
\hline $2-5$ years & 74 & 3.278 & 0.427 & & \\
\hline $6-10$ years & 108 & 3.245 & 0.393 & & \\
\hline 11 and above years & 84 & 3.223 & 0.447 & & \\
\hline
\end{tabular}

Table 5 results shows that the mean score on retention was high on academic staff with experience $2-5$ years $(\bar{x}=3.278)$, followed by academic staff with less than 2 years (mean of 3.270), followed by academic staff with experience between $6-10$ years $(\bar{x}=3.245)$. Lowest mean was observed on academic staff with experience 11 and above years $(\bar{x}=3.223)$. The computed $\mathrm{F}=0.27$ was smaller, since the probability $(\mathrm{p}=0.841)$ was bigger than $\alpha=$ 0.05. This implied that the retention of academic staff did not significantly depend on their years of teaching experience; therefore, the null hypothesis which states that "respondent's years of teaching experience do not significantly determine the retention of academic staff" was accepted and the research hypothesis that states that "respondent's years of teaching experience significantly determine the retention of academic staff" was rejected. This means that years of teaching experience of academic staff do not determine whether they may stay or leave working for Makerere or Kyambogo University.

4.1.6. Respondent's age and academic staff retention

The sixth null hypothesis on demographic characteristics that was tested concerned the effect of respondent's age on the retention of academic staff in the two universities studied. To perform the test, an index called academic staff retention (ASR) was generated and an Analysis of Variance (ANOVA) test was employed to determine whether there was a statistically significant difference in the retention of academic staff by age which was categorically and multi-coded as: Less than 30 years (coded as 1), 30 - 39 years (coded as 2), $40-49$ years (coded as 3)), $50-59$ (coded as 5), and 60+ years (coded as 5). The ANOVA-test results are presented in Table 6.

Table 4.6: Respondent's Age and Academic Staff Retention

\begin{tabular}{|c|c|c|c|c|c|}
\hline Age group & Sample size & Sample mean $(\bar{x})$ & Sample SD & $\mathrm{F}$ & $\mathrm{P}$ \\
\hline Less than 30 years & 21 & 3.112 & 0.105 & \multirow[t]{5}{*}{0.748} & \multirow[t]{5}{*}{0.560} \\
\hline 30-39 years & 117 & 3.264 & 0.035 & & \\
\hline $40-49$ years & 105 & 3.262 & 0.399 & & \\
\hline $50-59$ years & 42 & 3.230 & 0.072 & & \\
\hline $60^{+}$years & 13 & 3.308 & 0.123 & & \\
\hline
\end{tabular}

The results in Table 6 showed that the mean score on employee retention highest for academic staff in age group between 60 and above years $(\bar{x}=3.308)$, followed by those in age group 30-39 years $(\bar{x}=3.264)$, followed by those in age group 40-49 years $(\bar{x}=3.262)$, followed by those in age group between 50-59 years $(\bar{x}=3.230)$. Academic staff in age group less than 30 years scored lowest $(\bar{x}=3.112)$. The computed $\mathrm{F}=0.748$ was small because the probability or level of significance $(p=0.560)$ was greater than $\alpha=0.05(p>0.05)$. This implied that the retention of academic staff did not significantly depend on their ages; therefore, the null hypothesis which states that "respondent's age does not significantly determine the retention of academic staff" was accepted and the research hypothesis that states that "respondent's age significantly determine the retention of academic staff" was rejected. This means that the age of an academic staff does not determine whether they may stay or leave working for Makerere or Kyambogo University.

\subsection{Testing of Null Hypothesis Two}

The second main null hypothesis in this study was aimed at testing the effect of interpersonal relations on the retention of academic staff in the two universities studied. To perform the test, an index called academic staff retention (ASR) and another index call interpersonal relationships (IPR) were generated, and a simple linear regression analysis was performed to determine if ASR significantly depended on IPR. The results of the regression analysis are presented in Tables 7,8 and 9. 
Table 7: Regression Analysis Model Summary on IPR and ASR

\begin{tabular}{|c|c|c|c|c|}
\hline Model & $\mathrm{R}$ & $\mathrm{R}$ Square & Adjusted R Square & Std. Error of the Estimate \\
\hline 1 & $.003^{\mathrm{a}}$ & .000 & -.003 & .40928 \\
\hline
\end{tabular}

a. Predictors: (Constant), IPR

Table 8: ANOVA results on IPR and ASR

\begin{tabular}{|l|l|l|l|l|l|l|}
\hline \multicolumn{2}{|l|}{ Model } & Sum of Squares & df & Mean Square & F & Sig. \\
\hline \multirow{4}{*}{1} & Regression & .000 & 1 & .000 & .003 & $.957^{\mathrm{b}}$ \\
\cline { 2 - 7 } & Residual & 49.583 & 296 & .168 & & \\
\cline { 2 - 7 } & Total & 49.583 & 297 & & & \\
\hline
\end{tabular}

a. Dependent Variable: ASR

b. Predictors: (Constant), IPR

Table 9: Regression Analysis Co-efficient on IPR and ASR

\begin{tabular}{|l|l|l|l|l|l|l|}
\hline \multirow{2}{*}{ Model } & Unstandardized Coefficients & Standardized Coefficients & \multirow{2}{*}{ T } & Sig. \\
\cline { 3 - 8 } & B & Std. Error & Beta & & \\
\hline \multirow{2}{*}{1} & (Constant) & 3.259 & .177 & & 18.420 & .000 \\
\cline { 2 - 8 } & IPR & -.003 & .047 & -.003 & -.054 & .957 \\
\hline
\end{tabular}

a. Dependent Variable: ASR

Results in Tables 7 to 9 show that interpersonal relationships explained only 3\% of the variation in ASR (Adjusted $\mathrm{R}^{2}=-0.003$ ). This means that over 97 percent of the variation was accounted for by other extraneous variables not considered in the study. The regression model was bad $(F=0.003, p=0.957, p>0.05)$. The null hypothesis which states "interpersonal relationships do not significantly determine academic staff retention" was accepted and the research hypothesis which states that "interpersonal relationships significantly determine academic staff retention" was rejected. This means that IPR does not determine whether an academic staff may stay or leave working for Makerere or Kyambogo University.

\subsection{Testing of Null Hypothesis Three}

The third main null hypothesis in this study was aimed at testing the effect of terms of work on the retention of academic staff in the two universities studied. To perform the test, an index called academic staff retention (ASR) and another index called terms of work (TOW) were generated, and a simple linear regression analysis was performed to determine if ASR significantly depended on TOW. The results of the regression analysis are presented in Tables 10 to 12 .

Table 10: Regression Analysis Model Summary on TOW and ASR

\begin{tabular}{|l|l|l|l|l|}
\hline Model & R & R Square & Adjusted R Square & Std. Error of the Estimate \\
\hline 1 & $.163^{\mathrm{a}}$ & .027 & .023 & .40382 \\
\hline
\end{tabular}

a. Predictors: (Constant), TOW

Table 11: ANOVA Results on TOW and ASR

\begin{tabular}{|l|l|l|l|l|l|l|}
\hline \multicolumn{2}{|l|}{ Model } & Sum of Squares & df & Mean Square & F & Sig. \\
\hline \multirow{4}{*}{1} & Regression & 1.315 & 1 & 1.315 & 8.064 & $.005^{\mathrm{b}}$ \\
\cline { 2 - 7 } & Residual & 48.268 & 296 & .163 & & \\
\cline { 2 - 7 } & Total & 49.583 & 297 & & & \\
\hline
\end{tabular}

a. Dependent Variable: ASR

b. Predictors: (Constant), TOW

Table 12: Regression Analysis Co-efficient on TOW and ASR

\begin{tabular}{|l|l|l|l|l|l|l|}
\hline \multirow{2}{*}{ Model } & \multicolumn{2}{|l|}{ Unstandardized Coefficients } & Standardized Coefficients & \multirow{2}{*}{ Sig. } \\
\cline { 2 - 8 } & \multicolumn{1}{|c|}{ B } & Std. Error & Beta & & \\
\hline \multirow{2}{*}{1} & (Constant) & 2.835 & .148 & & 19.182 & .000 \\
\cline { 2 - 8 } & TOW & .122 & .043 & .163 & 2.840 & .005 \\
\hline
\end{tabular}

a. Dependent Variable: ASR

Results in Tables 10 to 12 show that terms of work explained only 23 percent of the variation in ASR (Adjusted $\mathrm{R}^{2}=0.23$ ). This means that 77 percent of the variation was accounted for by extraneous variables, other factors not considered in the study. The regression model was good $(F=8.064, p=0.005, p>0.05)$. The null hypothesis which states that "terms of work do not significantly determine the retention of academic staff" was rejected in favour of the research hypothesis which states that "terms of work significantly determine retention of academic staff”. This means that TOW significantly determines ASR in Makerere and Kyamobogo universities. 


\subsection{Testing of Null Hypothesis Four}

The fourth main null hypothesis in this study was aimed at testing the effect of work-life balance on the retention of academic staff in the two universities studied. To perform the test, an index called academic staff retention (ASR) and another index called work-life balance (WLB) were generated, and a simple linear regression analysis was performed to determine if ASR significantly depended on WLB. The results of the regression analysis are presented in Tables 13 to 15 .

Table 13: Regression Analysis Model Summary on WLB and ASR

\begin{tabular}{|l|c|l|l|l|}
\hline Model & $\mathrm{R}$ & R Square & Adjusted R Square & Std. Error of the Estimate \\
\hline 1 & $.318^{\mathrm{a}}$ & .101 & .098 & .38809 \\
\hline
\end{tabular}

a. Predictors: (Constant), WLB

Table 14: ANOVA Results on WLB and ASR

\begin{tabular}{|l|l|l|l|l|l|l|}
\hline \multicolumn{2}{|l|}{ Model } & Sum of Squares & df & Mean Square & F & Sig. \\
\hline \multirow{4}{*}{1} & Regression & 5.002 & 1 & 5.002 & 33.214 & $.000^{\mathrm{b}}$ \\
\cline { 2 - 8 } & Residual & 44.581 & 296 & .151 & & \\
\cline { 2 - 7 } & Total & 49.583 & 297 & & & \\
\hline
\end{tabular}

a. Dependent Variable: ASR

b. Predictors: (Constant), WLB

Table 15: Regression Analysis Co-efficient on WLB and ASR

\begin{tabular}{|l|l|l|l|l|l|l|}
\hline \multicolumn{2}{|l|}{ Model } & \multicolumn{2}{l|}{ Unstandardized Coefficients } & Standardized Coefficients & t & \multirow{2}{*}{ Sig. } \\
\cline { 3 - 8 } \multicolumn{2}{|l|}{} & B & Std. Error & Beta & & \\
\hline \multirow{2}{*}{1} & (Constant) & 2.688 & .100 & & 26.888 & .000 \\
\cline { 2 - 8 } & WLB & .171 & .030 & .318 & 5.763 & .000 \\
\hline
\end{tabular}

Results in Tables 13 to 15 show that WLB explained 98 percent of the variation in ASR (Adjusted $\mathrm{R}^{2}=0.098$ ). This means that only 2 percent of the variation was accounted for by extraneous variables, other factors not considered in the study. The regression model was good $(\mathrm{F}=33.214, \mathrm{p}=0.000<0.05)$. Thus the null hypothesis which states that "work-life balance does not significantly determine the retention of academic staff" was rejected in favour of the research hypothesis which states that "work-life balance significantly determines retention of academic staff". This means that WLB significantly determines ASR in Makerere and Kyamobogo universities.

\section{Discussion}

In this study, the following key findings were made. First, demographic factors such as respondent's gender $(\mathrm{t}=$ $2.556 ; p=0.006<0.05)$ were found to have significant effect on the retention of academic staff in Makerere and Kyambogo universities. This finding is in agreement with the work of other scholars such as Muir and Li (2015) who revealed that the retention rates of female academic staff in the US was relatively lower than that of their male counterparts. In the current study, however, the mean retention rate of female members of academic staff $(\bar{x}=3.34)$ was higher than that of their male counterparts $(\bar{x}=3.91)$. This difference could be attributed to cultural differences between the US and Uganda where women tend to get more settled once they are employed than the males.

Second, the study also found out that demographic factor such as respondent's marital status $(\mathrm{F}=0.288 ; \mathrm{p}=$ $0.750>0.05)$, age $(F=0.748 ; p=0.560>0.05)$, experience $(F=0.270 ; p=0.841>0.05)$, education level $(F=$ $0.528 ; p=0.663>0.05)$ have no significant effect on the retention of academic staff in the two universities studied. These findings were also in consonant with the work of other scholars such as Hayes (2015) who discovered that academic staff retention is not significantly predicted by the levels of education of the academic staff. However, according to Kumar and Arora (2012), several of these demographic factors including age and levels of education have significant impact on the retention of academic staff. The results of the current study meanwhile proved otherwise.

Third, the current study also revealed that terms of work $(B=0.163 ; p=0.005<0.05)$ and work-life balance $(B=0.318 ; p=0.000<0.05)$ are significant predictors of academic staff retention in Makerere and Kyambogo universities. These findings were in agreement with the work of Rathakrihnan et al. (2016) and Tanwar and Prasad (2016) who also discovered that the turnover intentions of academic staff basically depends on their perception of terms of work as well as work-life balance. This view was shared by Watanabe and Falci (2014) who opined that the stability of academic staff on their job significantly depended on their perception of work-life balance. The two authors also argued that high work pressures in any work setting have negative spill-overs on work-life balance; and consequently, on turnover intentions. In this study, the researchers managed to confirm some of the earlier findings but also discovered contradictory findings that can generally enrich the scholarly debate concerning factors that determine the retention of academic staff in universities. 


\section{Conclusion and Recommendations}

Basing on the study findings discussed above, the researchers concluded that certain factors were more critical than others in determining the retention of academic staff, other factors notwithstanding. As a result, the researchers recommended for the management of the two universities to put in place engendered policies that can improve on the terms of work especially those that allow academic staff balance teaching with research and community outreaches, favourably treat men and women in terms of offering promotions, job benefits and in dealing with gender sensitive issues when offering promotions, assessing their performance and when assigning work responsibilities, and allow for optimal work-life balance amongst the academic staff.

\section{References}

Albagami, A. (2016). Determinants of Turnover Intention Among Faculty Members in Saudi Public Universities. A dissertation submitted in partial fulfillment of Doctor of Philosophy in Business, University of Sanford, South Africa

Baker, J. A, et al., (2015). Factors affecting Female Lecturer retention in private higher institution in Perak, International Journal of Public Administration, $26 \quad$ (12), 1307-1336. http:/dx.doi.org/10.6007/IJARBSS/U5.i1/1410

Coetze, M., Oosthuizen, M. \& Stoltz, E. (2015). Psychological employability attributes as predictors of staff satisfaction with retention factors. South African Journal of Psychology 46 (2), 232-243. Doi:10:1177/008124631559597

Erasmus, B. J. Gobler, A., \& Niekerk, R. (2015).Employee retention in a higher education institution. An organizational Development Perspective, Progressio, 37 (2), 32-62

Gbenu, J. P. (2013), Academic staff turnover, National Development and emerging policy issues. Scholars Journal of Arts, Humanities and Social Sciences, 1(1), 1-7, http://saspjournals.com/sjahss

Hayes, T. C. (2015). Demographic characteristics predicting employee turnover intentions'. Doctoral study submitted in partial fulfilment of the requirement for the doctor of Business Administration in Walden University College of Educational Technology. http://cholarork.weldenu.edu/dissetations

Hong, E. M., Hao, L. Z., Kumar, R., Ramendran, C., \& Kadiresan, V. (2012). An effectiveness of human resource management practices on employee retention in institute of higher learning: A regression analysis. International Journal of Business Research and Management (ISBRM), 3(2), 60-79, http.//www.cscjournals.org.manu.script./journal/IJBRM/volum

Holmes, P. H., Bughurst, T. and Chapman, T. (2013). Employee job embeddedness. Why people stay. International Business Management and Economic Resources, 4 (5), 502-813. www.ijbmer.com

Janhua, Y. (2016. An empirical study on antecedents of employee retention and turn over intentions of employees. International Journal of Research in Business Management, 4(5), 1-10, www.impactjournals.

Korantwi-Barimah, J. S. (2017). Factors influencing the retention of academic staff in Ghananian Technical University. Human Resource Management Research, 7(3),111-119. doi:10.5923/jhrm,20703.03

Kubler, J., \& Deluca, C. (2006). Trends in academic recruitment and retention: A commonwealth perspective. The Association of Commonwealth Universities, ACU. whole report pdf

Kumar, R. and Arora, R. (2012). Determinants of talent retention in BPO industry. The Indian Journal of Industrial Relations, 48 (2), 259-273. http: //www.jstor.org/stable/23509837

Kyndt, E. Dochy, F., Michielson, M. \& Moeyaert, B. (2009). Employee retention organization and employee perspectives. Vocations and learning. Springer science; Business Media.Biv.doi:10.1007/si2186-009-9024-7

Long, S. L., Ajagbe, M. A., Nor, K. M., \& Suleiman, E. S. (2012). The impact of human resource management practices on employees' turnover intention: A conceptual model. Interdisciplinary Journal of Contemporary Research Business, 4, 2. Ijerb.webs.com

Mapolisa, T. (2014). Regressive staff retention. Challenges in Zimbabwe's public and private Universities. Selected retained lecturers perceptions. Journal of Educational policy and Entrepreneurial Research (JEPER). 1 (4), 92- 102. http,//www.iiste.org/journals/index.php/JEPER.

Masum, A. K. M., Azad, M. A. K. \& Beh, L. S. (2015). Determinants of academics satisfaction. Empirical evidence from private universities in Bangladesh. Journal of Pune, 10 (2), 25-32 https://doi:org/10.1371/journal.pune.0117834

Miller, A. (2013). Principal turnover and student achievement economics. Education Review, 30 (60- 72). doi:10:1016/j.econedurev.2013.05.004

Muir, M. R.,\& Li, L. (2014). What are the Top Factors that Drive Retention. Are they Demographic (gender, generation, ethenicity, geography etc.) Differences in These Factors. Cornell University. Digital commons @ ILR.http://digitalcommon.ilr.cornll.eu/student

Nawaz, N., Jahanian, A., \& Tahreem, S. (2012). Determinants of employee retention in Pakistan International Airlines P/A. European Journal of Business and Management, 4 (7), 45-53. www.iiste.org.

Ng'ethei, I., Iravo, E. M. \& Namusonge, G. S. (2012).Determinants of academic staff retention in public 
universities in Kenya. International Journal of Humanities and Social Science, 2 (13), 205-212. www.ijhssnet.com.

Ngobeni, E. K. \& Bezuidenhoint, A. (2011). Engaging Employees for Improved Retention in Higher Education in South Africa. African Journal of Business Management, 5(23), 9961 - 9970. http://www.academicjournals.org/AJBM

Rathakrishnan, T., Imm \& Kok. (2016). Turnover initiations of lecturers in private universities in Malaysia: Journal of Social Sciences and Humanities, 24(5), 129-146, http://www.pertanika.upm.edu.my/

Rwendeirwe, A. (2017). Bringing the Future to the Present. The Report of the Visitation Committee on Makerere University. Uganda Government, Kampala

Tanwar, K., \& Prasad, A. (2016). Exploring the relationship between employer branding and employee retention. Global Business Review, 17 (35), 1865-2065, doi:10.117/0972.150916631214

Tettey, W. J. (2006). Staff retention in African universities: Elements of sustainable strategy. World Bank.

Vandeberghe, C. and Ok, A. B. (2013). Career commitment, proactive personality and outcomes. Across lagged study. Career Development International, 18 (9), 652-672, doi: 10-1108/CDI-02-2013).

Vardamann, J. M., Allen, D. G., Otondo, R. F., Hancock, J. I., Shore, L. M. \& Rogers, B. L. (2016). Social comparisons and organizational support. Implications for Commitment and Retention Human Relations. Journal of Permissions, 21, 1-23, doi:10:1177/0018726715619687

Victoria, A. O. \& Olalekan, A. V. (2016). Effects of demographic factors on employees initiation to leave in selected private universities in south west, Nigeria. The International Journal of Business and Management, 4(10), 322-330, www.theijbm.com

Watanabe, M. \& Falci, C. (2015). A demands and resources approach to understanding Faculty turnover intentions due to work family balance. A Journal of Family Issues, 37 (3), 393-415. doi:10.1177/0192513x14530

Young, J. A., Aliang and Shuck., (2013). Job Embeddedness Theory. Can it explain employee retention among extension agents. Journal of Extension, 54(4), 1-11, www.joe.org. 